\title{
Effects of Abnormal Early Rearing Environments on Fear Memory in Adult Rats
}

\author{
LI Chuan-yu ${ }^{1,3, \#}$, ZHANG Bo ${ }^{2, \#, ~ L I ~ Z h e n-b a n g ~}{ }^{1}$, HUANG Fu-lian ${ }^{1}$, \\ TIAN Shao-wen ${ }^{1, *}$, HU Xin-tian ${ }^{3, *}$ \\ (1. Department of Physiology, Medical college, Nanhua University, Hengyang Hunan 421001, China; \\ 2. Section of Primate Neuroscience Research Laboratory and Key Laboratory of Animal Models and Human Disease Mechanisms, Kunming \\ Institute of Zoology, the Chinese Academy of Sciences, Kunming Yunnan 650223, China; \\ 3. Laboratory of Sensory-motor Integration Research and Key Laboratory of Animal Models and Human Disease Mechanisms, Kunming \\ Institute of Zoology, the Chinese Academy of Sciences, Kunming Yunnan 650223, China)
}

\begin{abstract}
In the present experiment, Pavlovian fear conditioning was adopted to study the effects of different early rearing environments on fear conditioning in adult rats. Weaned rats were reared in three manipulable environments (enriched, social and isolated conditions). After 8 weeks, fear conditioning (characterized by percentage of freezing) was observed and analyzed, and rats' weight, locomoter activity and foot-shock sensitivity were operated too. The results showed that: (1) Compared with control group, the level of conditioned fear was significantly increased in enriched group, but significantly decreased in isolated group; (2) Enriched and isolated conditions influenced rat's weight significantly; (3) Different rearing conditions have no effect on locomoter activity and foot-shock sensitivity. These results indicated that early enriched condition could improve the tone-evoked fear conditioning response, while isolated condition impaired the response.
\end{abstract}

Key words: Fear conditioning; Freezing; Enriched condition; Isolated condition; Locomoter activity; Foot-shock sensitivity

\section{大鼠成年前异常生活环境对其成年后恐惧记忆的影响}

\author{
李传玉 ${ }^{1,3, \#}$, 张 波 ${ }^{2, \#}$, 李振邦 ${ }^{1}$, 黄伏连 ${ }^{1}$, 田绍文 ${ }^{1, *}$, 胡新天 ${ }^{3, *}$ \\ (1. 南华大学 医学院生理教研室, 湖南 衡阳 421001; \\ 2. 中国科学院昆明动物研究所 灵长类认知实验室及动物模型和人类疾病机制重点实验室, 云南昆明 650223 ; \\ 3. 中国科学院昆明动物研究所 灵长类感觉-运动整合及动物模型和人类疾病机制重点实验室, 云南 昆明 650223)
}

\begin{abstract}
摘要: 为了探讨早期饲养环境对成年后大鼠条件化恐惧的影响, 实验采用巴氏恐惧条件化的方法对不同饲养环境 下的大鼠进行了行为检测。具体操作为: 把断奶后的大鼠饲养在 3 个不同的人工控制的环境中 (丰富环境、社群环 境和贫㾑环境）；8周后进行恐惧条件化训练和测试（指标为偪直百分比）, 以及检测不同饲养环境下的大鼠的体 重、自发活动和足部电击敏感性。结果显示: 与社群组相比, 丰富组的大鼠条件化僵直水平明显增加, 而贫㾑组 的明显减少; 丰富和贫㾑环境明显的影响了大鼠的体重; 不同环境对自发活动和足部电击敏感性没有影响。这些 结果说明幼年期的丰富环境能提高成年后大鼠的由声音诱发的条件化恐惧反应，而贫㾑环境则削弱了这种反应。
\end{abstract}

关键词：恐惧条件化；僵直；丰富条件；贫㾑条件；自发活动；足部电击敏感性

中图分类号: Q42; Q959.837 文献标识码：A 文章编号：0254-5853(2009)01-0031-07

Received date: 2008-08-04; Accepted date: 2008-12-24

Foundation items: National Natural Science Foundation of China(30770689); Scientific Research Fund of Hunan Provincial Education Department (05B045); National Basic Research Program of China (2002CB410803-04)

"Corresponding author（通讯作者), E-mail: tsw.neuro@126.com; xthu@mail.kiz.ac.cn

\# These authors contributed equally to this work

收稿日期：2008-08-04; 接受日期：2008-12-24

\#并列第一作者 
In animal model studies, depression and anxiety models were often established by rearing weaned rats in different artificially manipulated early environments to induce chronic behavioral and physiological changes (Hindmarch et al, 1999; Nemeroff et al, 1999; Pryce et al, 2005). Early environments consist of social factors and non-biological factors. Social factors include contacting with companion and non-biological factors refer to composition of the environment. Rich and isolated conditions are two extreme environmental conditions compared with social condition (normal rearing environment). Rich condition comprises of social environment enrichment (for example many animals reared together to increase social contacts), enriched incentives (for example keeping the novelty by replacing different objects regularly) and increasing visual and sensory-motor novelty in the environment. Isolated condition refers to rat separately rearing in a small space with only basic living materials. The two extreme conditions could affect the adult animal's neural plasticity, normal activity and potential mental pathological state (Varty et al, 2000).

Some researches found that rats reared in these two extreme early conditions showed some opposite characteristics. Compared with social condition, rich condition improved learning ability in some cognitive tasks, while isolated condition impaired learning ability. In the conditioned position preference (CPP) task, the rich condition group was more sensitive to amphetamines, but the sensitivity of isolated condition group reduced (Park et al, 1992; Bowling et al, 1993). Other researches found that isolated and rich groups showed similar characteristics, as both groups showed increased spontaneous activity, amphetamines induced stereotype behavior and cortical dopamine compared with control group (Bowling et al, 1994; Jones et al, 1992). Therefore, the effects of rich and isolated conditions on learning and memory were different in different kinds of learning models.

Then, what are the effects of different conditions on learning and memory in cued fear conditioning task? In the present experiment, Pavlovian fear conditioning paradigm was adopted to study different effects of early environments on fear learning and memory. Pavlovian fear conditioning has been widely used as a model of emotional learning and memory. In the paradigm, animals receive neutral stimulus (sound or light as conditioned stimulus, CSs) and aversive stimulation (foot-shock as unconditioned stimulus, USs), and after a number of training matches, neutral stimulus alone could cause animals' fear responses. Fear responses include physiological changes (such as heart rate and blood pressure increasing, respiration changing) and behavioral measures (such as behavioral freezing and fear potential of startle). After fear conditioning, repeated presentations of the CS in the absence of the US results in reduced probability and amplitude of the conditioned response and it is called extinction. Amygdala and prefrontal cortex (PFC) play an important role in fear learning and memory (Sotres-Bayon et al, 2006), and there are rich fiber connections between the two regions. Many studies have confirmed that amygdala plays a crucial role in acquisition and expression of fear memory, especially in association between neutral and aversive stimulations. PFC inhibits the expression of neutral-aversive stimulus association by projecting to amygdala to excite GABA-containing nerve fibers inside, so fear response is gradually weaken.

There have been reports concerned with the effects of early environments on fear conditioning. Environmental enrichment facilitated conditional freezing to an auditory CS (Briand et al, 2005; Barbelivien et al, 2006). Early life isolation stress impaired fear conditioning in adult rats (Kosten et al, 2006). The influence might be age related, as stress before puberty increased conditioned fear to the tone during adolescence but not during adulthood (Toledo-Rodriguez et al, 2007).

However, these studies adopted different manipulations before weaning or during the adulthood. There was no report that the treatments were given during adolescence and three different treatments were given at the same time as in the present study. The present experiment focused on the effects of early enriched and isolated environment conditions during adolescence on fear conditioning learning and memory.

\section{Materials and methods}

\subsection{Subjects}

The Subjects were 36 Sprague-Dawley male rats, 22 days old at the beginning of the experiment, obtained from the Laboratory Animal Center of University of South China, Hengyang, Hunan, China. After arrival, the rats were housed in a temperature- and humidity-controlled environment with ad libitum access to food and water. All animals were maintained on a light-dark cycle (lights on from 7:00 am to 7:00 pm, and 
testing occurred between 8:00 am and 5:00 pm). Experiments were conducted according to the National Institutes of Health Guide for the Care and Use of Laboratory Animals, and experimental protocols were approved by the Nanhua University Animal Care and Use Committee.

\subsection{Behavior apparatus}

Two observation chambers (without ceiling) (40 $\mathrm{cm} \times 40 \mathrm{~cm} \times 50 \mathrm{~cm}$; purchased from Shanghai Jiliang Software Technology Co. Ltd., Shanghai, China) were used in the present study. Walls of chamber A were constructed of black opaque plexiglas with white round figures $(4 \mathrm{~cm}$ in diameter) attached inside which spaced $3.5 \mathrm{~cm}$ apart. Chamber B was the same as chamber A except the figures were white rectangle $(30 \mathrm{~cm} \times 5 \mathrm{~cm})$ and spaced $5 \mathrm{~cm}$ apart. The floor of each chamber consisted of 25 stainless steel rods $(5 \mathrm{~mm}$ in diameter) and the distance between the centers of two rods was $1.5 \mathrm{~cm}$. The rods were connected to a shock source and solid-state grid scrambler for the delivery of foot-shock. The two chambers were situated in sound-attenuating cabinets (50 $\mathrm{cm} \times 50 \mathrm{~cm} \times 60 \mathrm{~cm}$ ) which were located in a brightly lit and isolated room. Illumination was provided by a $15 \mathrm{~W}$ white house light mounted on the ceiling of the cabinet, and a $80 \mathrm{~dB}$ noise was supplied by a buzzer in the cabinet as conditioned stimulus. There was a light-emitting diode fixed on one wall in each chamber as an indicating mark, and the diode emitted light when the noise sets on. The chamber was washed with $50 \%$ alcohol solution and $1 \%$ acetic acid solution prior to each subject's habituation, fear conditioning and test. Stimulus presentation was controlled by a computer program.

\subsection{Experimental design and procedures for behavioral testing}

1.3.1 Different groups and rearing conditions of rats The day pups were born was designated as postnatal day 0 (PND 0). On PND 22, pups were weaned and randomly assigned to three conditions. In enriched condition (EC), twelve rats were housed in a physically enriched cage. The cage consisted of rectangular wood floor and walls $(100 \mathrm{~cm}$ length $\times 70 \mathrm{~cm}$ width $\times 70 \mathrm{~cm}$ height), with roof covered with metal wire netting. Non-chewable plastic color toys, two PVC tubes (50 $\mathrm{cm} \times 15 \mathrm{~cm}$ and $25 \mathrm{~cm} \times 15 \mathrm{~cm}$, one is straight and another is crooked), a small running wheel and a shelter were randomly placed in the cage. The shelter and running wheel were kept in the cage throughout the experiment, while toys and tubes were changed once a week. Food dispensers and two water bottles were also rearranged every two days to create a novel environment and promote foraging behavior. In social condition (SC), four rats were housed in a cage $(45 \mathrm{~cm} \times 30 \mathrm{~cm} \times 20 \mathrm{~cm})$ which only contained food and water. In isolated condition (IC), rats were individually housed in a small polycarbonate cage $(30 \mathrm{~cm} \times 20 \mathrm{~cm} \times 12 \mathrm{~cm})$ which only contained food and water. Rats reared in three conditions were considered as EC group, SC group and IC group. Social condition (SC) was the normal rearing condition, and SC group was considered as the control group.

1.3.2 Fear conditioning and test Eight weeks after the grouping, behavior procedure was carried out. Rats were submitted to three experimental phases carried out on three consecutive days: habituation on day 1 , fear conditioning on day 2, fear conditioning test on day 3 . During habituation phase, rats were put into two observation chambers for $30 \mathrm{~min}$ respectively without tones and shocks presented. For fear conditioning, rats were transported from their home cages to the observation chambers to receive six CS-US pairings. CS was $4 \mathrm{kHz}, 80 \mathrm{~dB}, 20 \mathrm{~s}$ tone and US was $0.6 \mathrm{~mA}$ shock presented $0.6 \mathrm{~s}$ before the tone stopped and co-terminated with the tone. The average intertrial interval was $90 \mathrm{~s}$ (range 60-120s). Thirty seconds after the final shock, rats were returned to their home cages. For fear conditioning test, the procedure was the same as conditioning except 16 tone presentations alone without foot-shocks presented. For each rat, the conditioning chamber and test chamber were different, for example if the conditioning chamber was chamber $\mathrm{A}$, then the test chamber was chamber B.

Fear response to the tone CS was assessed by measuring freezing behavior. Freezing is the absence of all movements except those related to respiration. In each trial, freezing was timed and quantified by computing the percentage of the time spent freezing during each $20 \mathrm{~s}$ tone presentation. Freezing behavior was scored off-line from videotape with a digital stopwatch by an experimenter.

1.3.3 Body weight Prior to behavior procedure, electronic scale (Changshu, Jiangsu) was used to weight rats.

1.3.4 Locomotor activity test Locomotor activity test was conducted one day before habituation. Rats were transported to the locomotor test chambers $(40 \mathrm{~cm} \times 40$ $\mathrm{cm} \times 50 \mathrm{~cm}$ ) (Shanghai Jiliang Software Technology Co. Ltd.) from their home cages for $30 \mathrm{~min}$ and their 
behaviors were recorded as digital videos which were analyzed off-line by the commercial software provided by Shanghai Jiliang Software Technology Co. Ltd.

1.3.5 Foot-shock sensitivity test Foot-shock sensitivity was conducted after fear conditioning test. Rats were put into a chamber which was the same ground as the fear conditioning chamber but with a smaller size. The incremental amplitude of current flow was $0.05 \mathrm{~mA}$ with $0 \mathrm{~mA}$ as the basic current. Foot-shock sensitivity has three thresholds with respect to three different responses including noticing (orienting head movement), flinching (hind paws briefly raised off the rods), and vocalizing.

\subsection{Statistical analysis}

Statistical analysis was conducted using SPSS 13.0 software. Percentage of freezing values in fear conditioning and test sessions were analyzed using analysis of variance (ANOVA) with repeated measures. Post hoc comparison was performed with the LSD method. Additionally, Student's $t$-test was used in the body weight analysis, baseline freezing analysis, foot-shock sensitivity test and locomotor activity test. All

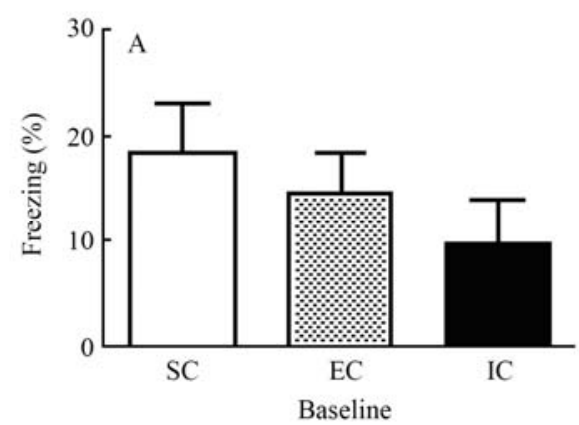

data were represented as mean \pm SEM. Differences were considered significant when $P<0.05$.

\section{Results}

\subsection{Baseline freezing and acquisition of fear conditioning}

In the cued fear conditioning task, there was no significant differences between groups with respect to the freezing response to the first tone presented (all $P>0.05$ ) (Fig. 1A). As shown in Fig. 1B, percentage of freezing varied significantly across trials $\left[F_{(5,160)}=45.238\right.$, $P<0.001]$, and ANOVA revealed significant differences between the first and following five trials (all $P<0.001$ ). But there was no significant difference between groups $\left[F_{(2,32)}=0.385, P=0.683\right]$. So all three groups acquired conditioned freezing response to tone rapidly across first three trials and then reached a plateau. Early environments did not alter the acquisition of conditioned fear response to tone significantly.

\subsection{Fear conditioning test and within-session acquisition of fear extinction}

One-way ANOVA revealed no significant differ-

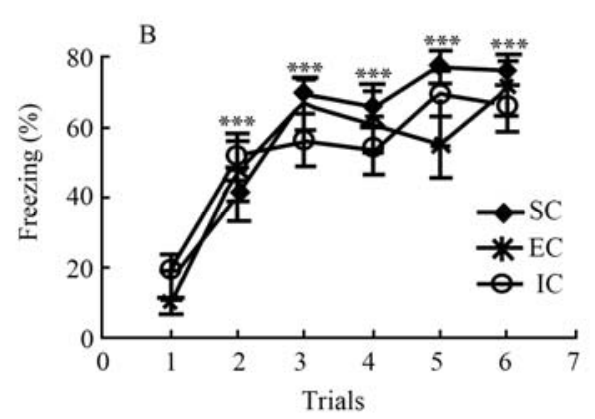

Fig. 1 Freezing response during fear conditioning

A: Percentage of freezing before the first foot-shock presentation during the first tone presentation of fear conditioning; B: Percentage of freezing response during acquisition of fear conditioning. $\mathrm{SC}=$ social condition, $\mathrm{IC}=$ isolated condition, $\mathrm{EC}=$ enriched condition. All data were represented as mean \pm SEM. $* * * P<0.001$.
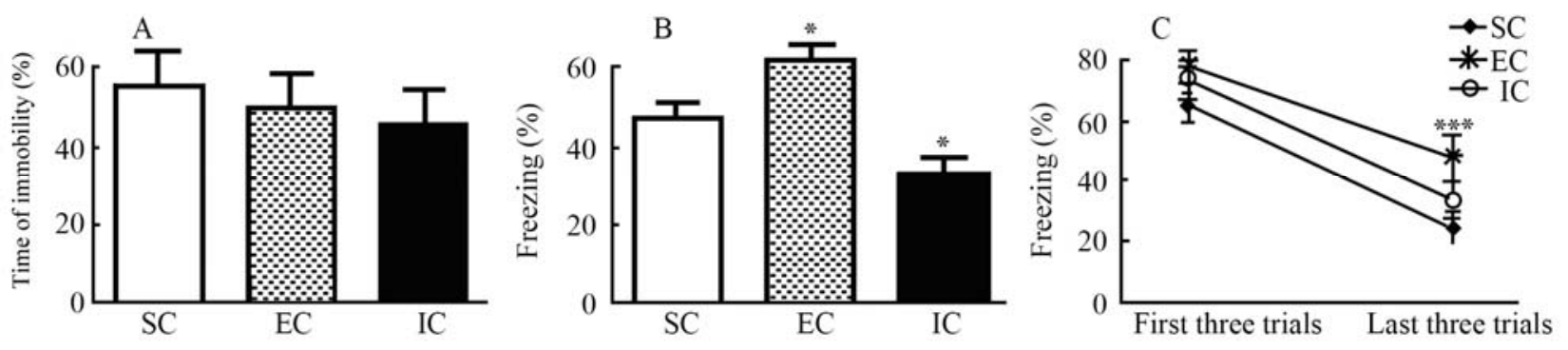

Fig. 2 Fear conditioning test and within-session extinction

A: Percentage of freezing during three minutes before fear conditioning test; B: Percentage of freezing during fear conditioning test; C: Within-session acquisition of extinction during fear conditioning test. $\mathrm{SC}=$ social condition, $\mathrm{IC}=$ isolated condition, $\mathrm{EC}=$ enriched condition. All data were represented as mean \pm SEM. $* P<0.05, * * * P<0.001$. 
rence between groups during the three minutes before fear conditioning test $\left[F_{(2,29)}=0.301, P=0.743\right]$ (Fig. 2A). As shown in Fig. 2B, ANOVA revealed significant difference between groups $\left[F_{(2,27)}=10.654, P<0.001\right]$. Post hoc comparison showed significant increase of freezing in EC group compared with control group $(P=0.026)$, significant decrease in IC group compared with control group ( $P=0.032$ ), and significant increase of freezing in EC group compared with IC group $(P<0.001)$. Taking together, these results indicated that early environments influenced fear response of adult rats, that is early enriched condition enhanced fear response while early isolated condition impaired fear response.

The ANOVA method also revealed significant difference between trials $\left[F_{(15,450)}=11.796, P<0.001\right]$, and between the first three and the last three trials $\left[F_{(1,30)}\right.$ $=64.8, P<0.001]$ as shown in Fig. 2C. Further analyses showed significant difference between first the three and last three trials within EC group $\left[F_{(1,9)}=10.790\right.$, $P=0.009]$, IC group $\left[F_{(1,10)}=20.814, P=0.001\right]$ and control group $\left[F_{(1,11)}=47.104, P<0.001\right]$. The data indicated abnormal early rearing environments did not significantly affected within-session acquisition of extinction.

\subsection{Nonspecific response measurements of rats reared in three different conditions}

\subsubsection{Body weight and sensitivity to foot-shock As}

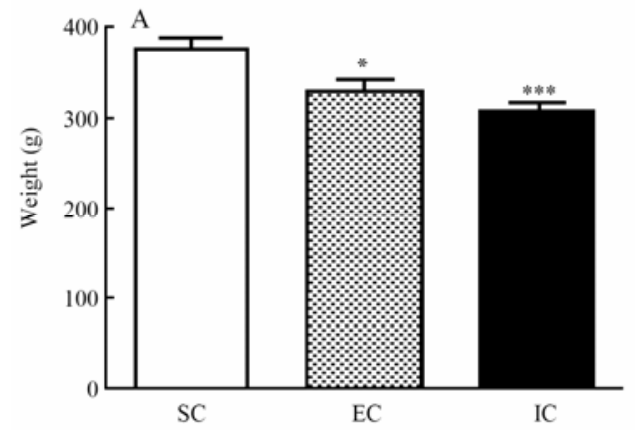

described in Fig. 3A, Student $t$-test showed that compared with control group, the average body weight of EC group and IC group showed a significant decrease [EC group $t=3.281, P<0.05$; IC group $t=5.362, P<$ $0.001]$, but there was no significant difference between EC group and IC group [ $t=1.419, P>0.05]$.

There was no significant difference between the three groups as concerned with thresholds to foot shock as indicated in Fig. 3B (all $P>0.05$ ). Thus, early environments did not significantly alter sensitivity to foot shock during fear conditioning.

2.3.2 Locomotor activity There was no significant difference in all groups and all indexes (all $P>0.05$ ) in locomoter activity test as shown in Tab. 1. Thus, early environments did not significantly change locomoter activity in adult rats.

\section{Discussion}

The present study demonstrated a specific effect on fear conditioning after cessation of environments handling in behavioral animal models. In fear conditioning phase, the freezing response during the first pair of tone and foot-shock was caused by the sound alone and taken as the baseline for tone. From the first match as described in Fig. 1A, different early environments have not affected the freezing response to the tone. That indicated that tone was only a clue and the change of freezing response was caused by association

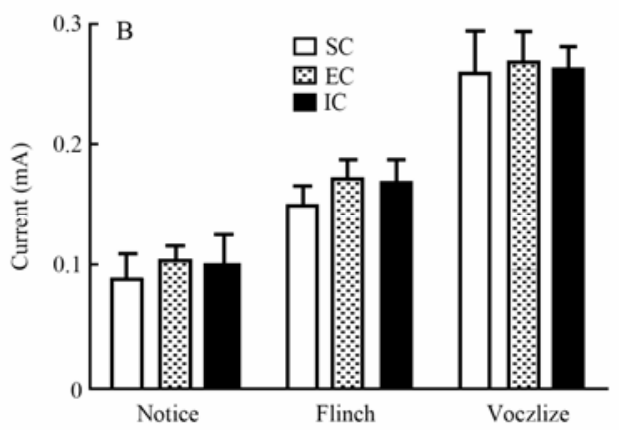

Fig. 3 Nonspecific response measurements of rats reared in three different conditions A: Mean weight of enriched $(n=10)$, social $(n=11)$ and isolated $(n=11)$ rats; B: Foot-shock sensitivity test in the enriched $(n=12)$, social $(n=11)$ and isolated $(n=11)$ rats. $\mathrm{SC}=$ social condition, $\mathrm{IC}=$ isolated condition, $\mathrm{EC}=$ enriched condition. All data are represented as mean $\pm \mathrm{SEM}$. All data were represented as mean \pm SEM. $* P<0.05, * * * P<0.001$.

Tab. 1 Rats' locomoter activity of different rearing conditions

\begin{tabular}{lllll}
\hline Group & Distance $(\mathrm{mm})$ & Time spent in center $(\mathrm{s})$ & Time spent in peripheral $(\mathrm{s})$ & Time of crossing $(\mathrm{s})$ \\
\hline Enriched & $81225.22 \pm 7597.18$ & $134.68 \pm 86.30$ & $1473.81 \pm 99.82$ & $67.51 \pm 17.22$ \\
Social & $74860.61 \pm 3250.19$ & $71.25 \pm 16.99$ & $1500.59 \pm 34.41$ & $65.42 \pm 9.20$ \\
Isolated & $87634.72 \pm 6958.21$ & $35.02 \pm 6.67$ & $1559.15 \pm 30.09$ & $54.33 \pm 10.17$ \\
\hline
\end{tabular}

All data were represented as mean \pm SEM. 
between tone and foot-shock stimulus. Freezing responses of all three groups increased rapidly across pairings tone with foot-shock repeatedly and then reached the "platform effect" throughout establishing of fear conditioning as reported before (Gu et al, 2007; Tian et al, 2008). That indicated all groups established equivalent level of fear conditioning, and it was prerequisite of fear conditioning test.

In the test session, the percentage of freezing response reflected the expression of fear conditioning. The results showed that early enriched environment could significantly improve auditory fear conditioning in adult rats, while isolated environment impaired auditory fear conditioning significantly. When tone presented repeatedly, the percentage of freezing response was gradually decreased in all three groups, but the differences between groups existed all the time. In the present experiment, different early rearing environments did not significantly affected within-session acquisition of extinction. As there was rare report concerned with the effects of abnormal early environments on acquisition of fear extinction, further research is needed. However, the result might be due to the fact that though both fear conditioning and extinction are new learning process, the mediating network and possible neural mechanisms are not the same (Sotres-Bayon et al, 2006).

Early environments had a significant impact on body weight of adult rats, as body weights of both enriched and isolated groups have reduced significantly compared with the control group. Although both enriched and isolated groups have reduced body weight, the reason could be different. Body weight reduction of enriched group could be due to increasing physical activities caused by novel objects, while reduction of isolation group might be due to less food intake and

\section{References:}

Barbelivien A, Herbeaux K, Oberling P, Kelche C, Galani R, Majchrzak M. 2006. Majchrzak. Environmental enrichment increases responding to contextual cues but decreases overall conditioned fear in the rat $[\mathrm{J}]$. Behav Brain Res, 169(2): 231-238.

Bowling SL, Rowlett JK, Bardo MT. 1993. The effect of environmental enrichment on amphetamine-stimulated locomotor activity, dopamine synthesis and dopamine release [J]. Neuropharmacology, 32(9): 885-893.

Bowling SL, Bardo MT. 1994. Locomotor and rewarding effects of amphetamine in enriched, social and isolate reared rats [J]. Pharmacol Biochem Behav, 48(2): 459-464.

Brenes Sáenz JC, Villagra OR, Fornaguera Trías J. 2006. Factor analysis of Forced Swimming test, Sucrose Preference test and Open Field test on depressed behavior caused by social isolation (Varty et al, 2000; Brenes Sáenz et al, 2006). In locomoter activity test, there was no significant differences between groups with respect to four indexes, early environments did not change the spontaneous activity of adult rats. As footshock sensitivity, there was no significant difference as concerned with the thresholds of attention response, flinching reaction and vocalizing response between all three groups. It indicated that early environments did not change the foot-shock sensitivity in adult rats.

The relationship between the early environments and fear conditioning was studied in the experiment. The results showed that early enriched condition can improve the tone-evoked fear conditioning response, and that might due to increasing of brain weight, cortical thickening and structural changes as reported by Rosenzweig et al and other reports (Huntley et al, 1972; Cavigelli et al, 2003). The results also showed that isolated condition impaired the fear response, and that might due to reduction of dendritic length, the number of dendritic spine and plasticity in adulthood caused by poor environment during juvenile stage (Silva-Gómez et al, 2003; Ferdman et al, 2007; Heidbreder et al, 2000).

Although early environments could modify fear conditioning response in adult rats, the concrete mechanisms including molecular and neurotransmitters' changes in this course remain unknown. Therefore, more researches are needed at the molecular level to achieve more information about brain development.

Acknowledgments: We thank CHEN YM (Section of Primate Neuroscience Research Laboratory and Key Laboratory of Animal Models and Human Disease Mechanisms, KIZ, CAS) very much, for who provided valuable suggestions on the data analyzing. enriched, social and isolated reared rats [J]. Behav Brain Res, 169: 57-65 Briand LA, Robinson TE, Maren S. 2005. Enhancement of auditory fear conditioning after housing in a complex environment is attenuated by prior treatment with amphetamine [J]. Learn Mem, 12(6): 553-556.

Cavigelli SA, McClintock MK. 2003. Fear of novelty in infant rats predicts adult corticosterone dynamics and an early death [J]. Proc Natl Acad Sci, 100(26): 16131-16136.

Ferdman N, Murmu RP, Bock J, Braun K, Leshem M. 2007. Weaning age, social isolation, and gender, interact to determine adult explorative and social behavior, and dendritic and spine morphology in prefrontal cortex of rats [J]. Behav Brain Res, 180(2): 174-182.

Gu CL, Li P, Hu B, Ouyang XP, Fu J, Gao J, Song Z, Han L, Ma YY, Tian SW, Hu XT. 2008. Chronic morphine selectively impairs cued fear 
extinction in rats: implications for anxiety disorders associated with opiate use [J]. Neuropsychopharmacol, 33(3): 666-673.

Heidbreder CA, Weiss IC, Domeney AM, Pryce C, Homberg J, Hedou G, Feldon J, Moran MC, Nelson P. 2000. Behavioral, neurochemical and endocrinological characterization of the early social isolation syndrome $[\mathrm{J}]$. Neuroscience, 100(4): 749-768.

Hindmarch I. 2001. Enlargement of the depression mould: further than of monoamines hypothesis [J]. Hum Psychopharm Clin , 16(1): 203-218.

Huntley MJ, Newton JM. 1972. Effects of environmental complexity and locomotor activity on brain weight in the rat [J]. Physiol Behav, 8(4): 725-727.

Jones GH, Hernandez TD, Kendall DA, Marsden CA, Robbins TW. 1992. Dopaminergic and serotonergic function following isolation rearing in rats: Study of behavioural responses and postmortem and in vivo neurochemistry [J]. Pharmacol Biochem Behav, 43(1): 17-35.

Kosten TA, Lee HJ, Kim JJ. 2006. Early life stress impairs fear conditioning in adult male and female rats [J]. Brain Res, 1087(1): 142-150.

Nemeroff CB. 1999. The preeminent role of early untoward experience on vulnerability to major psychiatric disorders: the nature-nurture controversy revisited and soon to be resolved [J]. Mol Psychiatry, 4(2): 106-108.

Park GA, Pappas BA, Murtha SM, Ally A. 1992. Enriched environment primes forebrain choline acetyltransferase activity to respond to learning experience [J]. Neurosci Lett, 143(1-2): 259-262.

Pryce CR, Rüedi-Bettschen D, Dettling AC, Weston A, Russig H, Ferger B, Feldon J. 2005. Long-term effects of early-life environmental manipulations in rodents and primates: Potential animal models in depression research [J]. Neurosci Biobehav Rev, 29(4-5): 649-674.

Silva-Gómez AB, Rojas D, Juárez I, Flores G. 2003. Decreased dendritic spine density on prefrontal cortical and hippocampal pyramidal neurons in postweaning social isolation rats [J]. Brain Research, 983 (6): 128-136.

Sotres-Bayon F, Cain CK, LeDoux JE. 2006. Brain mechanisms of fear extinction: historical perspectives on the contribution of prefrontal cortex [J]. Biol Psychiatry, 60(4): 329-336.

Tian SW, Gao J, Han L, Fu J, Li C, Li Z. 2008. Prior chronic nicotine impairs cue fear extinction but enhance contextual fear conditioning in rats [J]. Neuroscience, 153(4): 935-943.

Toledo-Rodriguez M, Sandi C. 2007. Stress before puberty exerts a sex- and age-related impact on auditory and contextual fear conditioning in the rat [J]. Neural Plast, 2007: 1155-1167.

Varty GB, Paulus MP, Braff DL, Geyer MA. 2000. Environmental enrichment and isolation rearing in the rat: effects on locomotor behavior and startle response Plasticity [J]. Biol Psychiatry, 47(10): 864-873.

\section{《动物学研究》新年致谢编委、审稿人和作者}

鼠年即逝, 牛年即至。在这时光交替之际, 《动物学研究》编辑部全体工作人员向各位编委、审稿人 和作者道一声“新年好！”，并祝愿各位身体健康！晹家幸福！事业有成！

没有您审阅稿件、出谋划策、赐予稿件, 也就没有今天的《动物学研究》。衰心感谢您为《动物学研 究》所付出的努力和贡献!

2008 年本刊共收稿 498 篇。发表稿件约 98 篇，其中英文稿发表率占 $27 \%$; 年平均发表周期为 159 天。 本刊 2007 年总引频次核心版为 986, 扩展版为 1222 ; 影响因子核心版为 0.871 , 扩展版为 0.9222 ; 他引 率为 0.89 ; 在我国 58 种生物学类期刊中, 总引频次排名第 25 位, 影响因子排名第 12 位; 在中国 1765 种 科技期刊中，总引频次排名第 386 位，影响因子排名第 192 位（中国科学技术信息研究所《2008 年版中国 科技期刊引证报告（核心版）》）。借此向您汇报!

恭祝

节日快乐!

《动物学研究》编辑部 